Studia Anglica Posnaniensia 47/1, 2011

doi: 10.2478/v10121-010-0018-1

\title{
AN INTEGRATED APPROACH TO CONVENTIONALITY AND ITS IMPLICATIONS FOR THE SEMANTICS OF EMOTION TERMS
}

\author{
ARIADNA STRUGIELSKA
}

Nicolaus Copernicus University, Toruń

\begin{abstract}
The aim of this article is to demonstrate that an integrated methodology can shed a new light on the understanding of notions inherent in contemporary conceptual approaches to linguistic analysis. One of the key ideas around which the cognitive paradigm is built is conventionality. It is assumed, however, that various strands of the cognitive enterprise view conventionality in dissimilar ways. Consequently, by extrapolating diverse interpretations of the notion, we are going to argue that certain conceptual approaches are more cognitive than others. As a result, it will be argued that a conceptual metaphor methodology, an apparently dominant approach to the semantics of emotion terms, is too coarse-grained to account for the richness of cognitive processes observable in real data. Providing a corpus-assisted verification of selected instantiations of the attributive construction, we are going to argue that a conceptual metaphor approach cannot be successfully applied within a usage-based model.
\end{abstract}

\section{Introduction}

Dirven (2005: 17-18) sees Cognitive Linguistics as a diverse paradigm characterized by various internal ramifications, among which there is a "...phenomenology-based strand...explored by George Lakoff and Mark Johnson in the direction of 'embodied realism'... Here belong prototype theory, lexical network theory, conceptual metaphor theory, and conceptual metonymy theory with inroads into cognitive pragmatics".

A conceptual metaphor methodology should then be seen within the broad context of the cognitive paradigm, which is neatly characterized by "the Generalisation Commitment" and "the Cognitive Commitment" (Evans - Green 2006: 40), which will subsequently be referred to as the conceptualist commitment. The former sets out to establish recurring patterns within the language system 
disregarding traditionally imposed dichotomies. The latter represents the view that principles of linguistic structure should reflect what is known about human cognition from other disciplines, particularly the other cognitive sciences. It then follows that language and linguistic organisation should reflect general cognitive principles and phenomena, such as categorization or salience, which, in turn, are rooted in human embodied experience. In the same vein, Geeraerts (2006: 3-6) argues that Cognitive Linguistics is a model permeated with meaning, which is perspectival, dynamic, non-autonomous, usage-based.

However, as we are going to argue below, the degree to which a particular approach within the cognitive paradigm fulfils the conceptualist commitment varies. While corpus-based approaches relying on induction tend to abide by cognitive principles through the acknowledgement of fuzziness, dynamicity and flexibility of conceptual processes, top-down, introspective analyses seem to overlook a number of essential cognitive phenomena, e.g. semasiological and onomasiological salience or the granularity of construal.

These differences constitute the basis for positing isolating and integrating conceptual models, which are discussed below.

\section{Basic notions}

In line with the conceptualist commitment outlined above, a semantic theory should define meanings of linguistic expressions against the context of shared human experience. In other words, meanings need to be inextricably related to the cognitive processes underlying them. However, as Langacker (2008: 31) rightly observes, "[a]dmitting that meaning resides in conceptualization does not itself solve anything but merely lets us formulate the problem".

In fact, a particular definition of conceptualization adopted in a theory results in highlighting either its isolating or integrating tendencies (see Geeraerts 2003). To be more specific, isolating approaches tend to constrain the number of possible contexts influencing linguistic theorizing, while integrating methodologies allow the researcher to "...describe the entirety of language from discourse through lexis and culture to syntax and cognition" (Glynn 2004: 198).

The above proclivities result in a number of parameters according to which isolation and integration in conceptual models can be discussed. For instance, with reference to data analysis, the isolating methodology favours introspection, while the integrating approach relies on corpus studies. Moreover, dividing approaches employ an abstract and schematic metalangue, while in integrating methodologies semantic primitives are situated and specific (Zlatev 2005: 5).

Two implications of the isolating/integrating continuum are of particular relevance to the present discussion. The first one concerns the nature of meaning and the other pertains to the character of a theory's heuristic apparatus. As I 
am going to argue in Section 4, a number of terms proposed within a methodology could in fact be classified as inventions, since their definitions are not derived from naturally-occurring data but imposed by the analyst (see Hudson 2008: 283).

\section{The nature of meaning}

As already indicated above, a number of constructs employed in conceptual models are imposed rather than discovered. To illustrate, both lexical items and constructions are inventions in the sense that the notions entail enforcing specific boundaries upon language.

Alternatively, language can be seen as a continuum of units with fluctuating boundaries. Consequently, meanings can be understood as either detailed, static, rigid and finite inventories of senses, oscillating between rampant polysemy (Lakoff 1987) and monosemy (Goldberg 1995), or as meaning potentials (Vandeloise 1994; Kemmer 2005; Szwedek 2007).

For the sake of the present discussion, meaning is taken as an underspecified potential which is elaborated in the process of conceptual interaction. It is then the role of the context, including both linguistic and non-linguistic information, to spell out which element of the conceptual matrix is salient in particular circumstances. Moreover, no qualitative distinction is made into lexical and grammatical units. In other words, neither words nor constructions are taken as profile determinants (Taylor 2002: 349). Instead, the meaning of an utterance is considered as a whole, with a possible consequence that semantic contributions of individual linguistic units are impossible to discern. Meanings are thus distributed rather than localized (Langacker 2008: 29), and underspecified rather than predetermined.

There have been numerous detailed accounts of how semantic indeterminacy should be understood and what factors are to be taken as contributing to extrapolating the contextually relevant elements of meaning. These approaches to conceptual underspecification seem to differ according to the relative importance of linguistic as opposed to encyclopaedic knowledge in the process of meaning construction.

According to Allwood (2003: 43), the above dichotomy is irrelevant since words potentially include all manner of relevant information and, consequently, "...no attempt is made to distinguish between lexical and encyclopaedic information in terms of the kind of information that is contained in the meaning potential. Meaning potentials contain both kinds of information - information deriving from use of language and information deriving from other experience with the world". Likewise, Langacker (2008: 41) postulates that meanings are probabilistic and variable paths of access to domains of knowledge. In the same 
vein, Fauconnier and Turner (2002: 144) observe that the meaning of a word, i.e. the adjective safe, as in a safe beach or a safe bet, is "...not an invariant set of properties but, rather, a set of instructions for building a suitable conceptual integration network on the basis of the harm scenario". As a result, meanings are context-dependent and, consequently, they are a matter of becoming meaningful in the process of semantic integration.

For the sake of illustration, let us consider the adjective deep, which potentially evokes a number of conceptual domains as well as syntactic constructions. It stands to reason, for instance, that deep should be associated with a 3-dimensional container constituting a profiled area within the basic domain of space (Langacker 1987, 1). In terms of syntactic patterns, deep would probably be associated with a premodifier in a noun phrase, e.g. deep water, or a subject complement in a clause, e.g. The water is deep. The idealized semantic properties of deep seem to be taken as the conventional sense of the word in Conceptual Metaphor Theory (henceforth also CMT), as outlined in Lakoff and Johnson (1980).

However, introspective intuitions are not confirmed by a corpus-based verification. To illustrate, the most frequent nominal collocates of deep, extracted from the BNC, include: breath, water, voice, sea, end and sleep. Clearly then, the list does not include prototypical containers, such as boxes. Consequently, a conceptual metaphor postulates that the conventional sense of deep is rooted in the container schema does not seem to be confirmed by a corpus-based analysis. Moreover, real data do not corroborate the importance of topological depth for prototypical containers. Instead, functional properties are highlighted. To illustrate, the most frequent corpus collocates for box include: office, cardboard, letter, black, phone, signal, ballot, dispatch, or telephone. Importantly, the context of an utterance in which each of the above complex units is embedded, e.g. office box or cardboard box, highlights aspects important from the human perspective rather than abstract topological schemas. For instance, cardboard boxes tend to be used for protection or transportation, as illustrated by the following corpus examples:

1) Her pups were now piled together in a cardboard box lined with an old woollen jumper and several sheets of brown paper.

2) That night he slept in an old cardboard box that he'd found, and that gave him some protection from the chilling morning dew.

3) At the bottom of the garden, under the cherry trees, Isabel saw the low mound of earth, below which, two or three feet below, was the cardboard box, containing Faith's pieces of jewellery.

4) Mrs Janet Postance, Landscore's head, carries about with her a cardboard box which might once have held apples, now replaced with documents relating to the national curriculum, the Devon Education Authority curriculum and her own school curriculum. 
The above discrepancy between an idealized concept of a conventional sense and its usage-driven profile points to a crucial question concerning the definition and function of conventionality in the process of meaning construction.

\section{Conventionality}

The notion of conventionality is frequently evoked in conceptual models, which is probably related to its apparent role if establishing "primary" senses of linguistic units. The definitions of the term, however, are far from consistent. For instance, according to Clark (1996: 71), conventionality is a complex notion, which is manifested through a unit's regularity in behavior, its partial arbitrariness as well as prompt recognition within a language community. Moreover, in a usage-based model, conventionality is related to the effects of frequency, whereby type and token frequencies should be considered (Stefanowitsch 2006: 68). Furthermore, Langacker (2008: 227) argues that conventionality should encompass a unit's ability to act as a standard of comparison for "ill-formed" units. In other words, an expression is conventional if it conforms to the specifications of the schemas evoked for its classification.

Obviously, there could be various units participating in the assessment. For instance, a more conventional sense of a word is frequently taken as the standard against which other senses should be evaluated. Also, a well-entrenched example of a construction can be taken as a model against which other examples are viewed. As Langacker (2005) points out, there are many verbs that have a strong associative link to a particular construction, which he illustrates by means of a bidirectional collostructional pull between the verb give and the ditransitive construction. Thus, in a usage-based model, where frequency is a prominent parameter (Deignan 2005: 117), there is a highly conventionalized link between give and the ditransitive. This connection is obviously part of our knowledge of both the verb and the construction. In other words, the constructional pattern could be taken as a component of the conventional meaning of the word.

The above statement points to a connection between a definition of conventionality adopted in the model and the quantity and quality of linguistic data the approach chooses to take into consideration. This interdependence is neatly illustrated by the notion of a construction in Cognitive Linguistics.

To begin with, Goldberg (1995: 4) defines a construction as a pairing of form and meaning, where certain aspects of the schema are not predictable from its components. Hence, Goldberg defines constructions as conventional on the basis of one parameter of the concept - its idiosyncratic meaning. Consequently, a number of conventional linguistic units are placed outside the scope of the analysis. In fact, Taylor (2002: 567) argues that in Goldberg's model, a 
number of linguistic items are non-constructions, e.g. The farmer shot the rabbit, since their semantic properties are derivable from the meanings of the constructional schema and its component symbolic units. Similarly, Langacker (2005: 140) observes that "[i]n Construction Grammar, a construction is recognized only if some aspect of it is unpredictable from its component parts or other, independently established constructions". Thus, I love you would not be a construction in Goldberg's approach despite its high degree of entrenchment and familiarity within a speech community. To continue, Croft (2001) defines only non-atomic units as constructions. Consequently, individual words and word classes obtain their semantic definitions from the context. Otherwise, they are epiphenomenal and language-specific categories. Finally, Taylor (2002: 561) defines a construction as "... any linguistic structure that is analyzable into component parts".

The above exposition points to a strong association between the scale of conventionality and the type of data regarded as conventional, which can be further demonstrated on the basis of Conceptual Metaphor Theory.

\subsection{Conventionality in Conceptual Metaphor Theory}

In a conceptual metaphor approach, conventionality operates at the levels of metaphorical schemas and their linguistic instantiations. However, as I have already argued elsewhere (see Strugielska 2010), conceptual metaphors are in fact scientific classifications, in the sense of Ungerer and Schmid (1996: 61), rather than categories validated from a usage-based perspective. Consequently, cognitive schemas cannot be defined as entrenched since they are neither productive nor uniformly understood categories.

Nevertheless, CMT consistently defines metaphorical expressions as instantiations of conceptual mappings (Lakoff - Johnson 1980: 5). Moreover, since cognitive metaphors are assumed to be "....age-old and deeply entrenched ways of thought" (Kövecses 2002: 32), their linguistic realizations are conventional as well. Consequently, the proponents of CMT fail to view conventionality from the broader perspective employed by, for instance, Taylor (2002), and encompassing the criteria of frequency and productivity. Instead, the theory defines conventional language with reference to entrenched cognitive mappings. Consequently, in positing that conceptual metaphors determine the interpretation of linguistic examples, CMT resembles Goldberg's (1995) construction grammar. This similarity is reinforced by the fact that in CMT, a well as in Goldberg's model, a number of potentially relevant data are excluded from the analysis (Cameron 2003: 252).

Further evidence for an impoverished view upon conventionality, characteristic of isolating methodologies, e.g. Conceptual Metaphor Theory, is provided 
by Steen (2002: 21), who claims that frequency is not a prerequisite for entrenchment. This tendency of metaphor-based models, i.e. considering frequency as a non-salient aspect of conventionality, is confirmed by Deignan (2005: 95), who notes that the majority of conventional linguistic examples provided by conceptual metaphor researchers are in fact random occurrences. Moreover, productivity of linguistic examples is clearly not at issue in CMT since morphosyntactic details are ignored, and metaphorical expressions are in fact expression types rather than tokens (Stern 2000: 179). Clearly then, in CMT, conventionality tends to be interpreted as a relation between basic and extended senses of a word, which reflects the source/target distinction at the conceptual level.

For instance, Steen (2007: 289, 293) assumes that in order to precisely identify metaphorical language we need to find contrast between a contextual meaning and a more basic meaning of the word, where basicness is taken as the first and most physical sense listed in a dictionary. Since contextual modulations are limited, the same properties are in fact attributed to a variety of data. For instance, "the sudden growth of the economy" (Kövecses 2000: 43) signals intensity in the same way as "growing fear" (Stefanowitsch 2006: 81). Likewise, Kövecses (2000: 41) posits that deep rather uniformly relates to intensity, which entails that deep in both deep fear and, for instance, deep sleep highlights the same aspect. Moreover, there are a number of source domains which concentrate on the feature of intensity, e.g. heat and fire or natural forces. In a metaphor model, these source domains map their central aspect, i.e. intensity, onto a number of target concepts, e.g. love, hatred or curiosity (cf. Kövecses 2000: 113), which entails widespread synonymy among categories.

This objective definition of the main meaning focus of the source domain, as defined by Kövecses (2000: 110), implies that the conventional sense is a welldelineated, stable and fixed parameter. However, conventionality seems to be a matter of degree and subjective judgement, which is emphasized in corpusbased studies.

\subsection{Conventionality and corpus data}

The notion of conventionality is also present in data-driven approaches to abstract terms. For instance, Deignan (2005: 42) argues that the notion of a conventionalized metaphor relies on an active relationship between a literal sense of a word and an established metaphorical sense.

At the same time, however, the concept is seen as gradable since it is related to the speaker's subjective judgment concerning the degree to which the extended sense is conceptually dependent on the basic one. As Deignan (2005: 41) argues, the adjective deep, as in deep colour, evokes to her no connection be- 
tween the "measurement" and the "colour" senses of the word. Hence, deep in deep colour has lost its motivation and is, therefore, at least by some language users, classified as a dead metaphor. However, when deep is used in the context of emotions, e.g. deep fear, it is apparently dependent on the more basic sense of "measurement". Consequently, according to Deignan (2005: 45), the same lexeme can be classified as an instantiation of various types of metaphors. Moreover, Hanks (2006: 19-21) observes that, for certain linguistic units, the conventional sense cannot be established. To illustrate, he argues that the word realization cannot be felicitously analysed in terms of one sense having primacy over the remaining two. However, this does not preclude the possibility that for some language users the links among the senses are active.

What transpires from the above discussion is that fact that an active link between senses, upon which the notion of conventionality is based, becomes far less delineated and stable once real data are confronted. Consequently, conventionality seems to be a matter of degree.

\subsubsection{The case of deep revisited}

As already indicated above, when verified against a large corpus of examples, conventionality cannot be reduced to a fixed and rigid "core" sense. Still, the predominant view is that the conventional meaning of a linguistic unit is its "lexicalized meaning, i.e. the meaning retrievable from the mental lexicon rather than from the context" (Giora 1999: 919), which often leads researchers to posit a need for differentiating between "...lexical concepts, stored linguistic knowledge units, and cognitive models, conceptual knowledge structures which constitute the semantic potential that lexical concepts provide access to" (Evans 2006: 496).

However, in view of the conceptualist commitment outlined in Section 1, a linguistic analysis should not be flawed by rigid distinctions. Instead, as Boas (2003: 171) argues, the meaning of a word consists of minimum two components: the lexical and the encyclopaedic (cf. Haiman 1980), which form a continuum. Most importantly, though, the two aspects are evoked for meaning interpretation depending on the context in which a word is situated. While expected uses are associated with the lexical pole of the meaning potential, novel applications will require extralinguistic knowledge for felicitous understanding.

Thus, conventionality is not only gradable and fuzzy but also contextdependent. It may well be the case, then, that while some occurrences of a unit are sufficiently defined in terms of an idealized conventional sense, others will only be interpretable against a multifaceted context, where the main meaning focus is absent. To illustrate this gradation, let us analyse selected corpus data related to the attributive construction. 
As evidenced in Section 3 above, the most frequent domains to collocate with deep include water. Moreover, deep in deep water probably evokes a large portion of idealized knowledge associated with the adjective, e.g. its topological properties. Examples (5) to (13) below have been sampled from corpus data to illustrate this point.

5) At the far end a rocky promontory extended into deep water - a promising place for snorkelling.

6) The reefs in deep water off Devon and Cornwall are fairly clear and have given steady sport.

7) After buying or picking flowers recut stems and place in cool, deep water, up to neck level for at least two hours.

8) Unless replenished, many beaches gradually disappear as their sand is carried away into deep water.

9) The tide had turned long ago and the sea had slushed gently down the sands, withdrawing into its channels, then back into the deep water far out in the Estuary.

10) Firemen were called to the river Taff in Llandaff to rescue Eric, a 10-stone Irish Wolfhound who had got into deep water after deciding to go in for a swim.

11) So the ones we are looking for are all in deep water.

12) Third rod lands pike angler in deep water.

13) Please note, however, that the bottom shelves quickly into deep water.

Of the 166 citations retrievable from the corpus, as many as 76 refer to the topological properties of the container, which is signalled by the co-occurrence of deep water with containment prepositions (in, into, out of). Moreover, it should be noted that other elements of the linguistic context are rather varied since deep water appears together with numerous specific verbs (e.g. extend, place, carry away, withdraw). Next, deep water participates in syntactic patterns where it functions as a postmodifier (6), an obligatory (7), or an optional (8) adverbial. In other words, we could say that the meaning of deep in deep water is aligned with the relevant feature in the semantic structure of water. Consequently, little context is needed, probably only in the form of containment prepositions, to interpret this particular realization of the meaning potential of deep. Hence, the verbs and the syntactic constructions seem superfluous in the process of meaning elaboration.

A different picture emerges if we analyse examples including deep sleep.

14) There was no swinging pendulum and no "You are going into a deep, deep, deep sleep". 
15) Others may experience a light-headed sensation as if they have had a few glasses of wine; a few fall into a deep sleep!

16) She fell into deep sleep.

17) Then he slipped into a deep sleep.

18) She did not smile now but her eyelids with those amazing lashes slowly closed and Abigail gave a sigh, wriggled her body, moved her head and subsided back into deep sleep.

19) A question which remained obstinately hovering in her mind as she slowly slipped into a deep sleep.

20) He quietened down then, shaking his head like a man coming out of a deep sleep.

21) At very much the same hour Edmund Mortimer came out of the deep sleep that follows fever.

22) "Why don't I do the first half and you have an early night, and I'll wake you at two o'clock?", knowing full well how awful it is to be woken out of a deep sleep at 2 am to start work.

The most important tendency to be observed in the above examples is the uniformity of the context within which deep sleep occurs. While the prepositions in, into and out of occur in the contexts of both water and sleep, the verbs are now only of two kinds. The first group are highly schematic verbs, i.e. go and come, participating in numerous frames and performing a rather supporting function (Fillmore 1985: 224). The other group is constituted by verbs denoting lack of control: fall, subside, slip or consciousness: wake. The first set of verbs, due to their schematicity, is taken as not contributing much to the semantics of deep sleep. The other group is seen as highly informative since they refer to salient cognitive (or perceptual) features (Hanks 2006: 20). In other words, both (lack of) control and consciousness are vital for human condition.

The other important tendency is the convergence between the meaning of the verbs and the meaning of the syntactic patterns. As evidenced above, deep sleep occurs with the intransitive construction, the copular pattern, and the passive construction. Clearly, then, all the sentence-level schemas share the element of a passive human participant, which corresponds to the semantic element highlighted by the relevant verbs.

Comparing the meanings of deep in deep water and deep sleep, we can firmly state that deep does not uniformly display an idealized conventional meaning. Rather, there is a certain meaning potential associated with deep which is elaborated according to context. In the case of deep water, the meaning potentials of deep and water are compatible. In terms of Stefanowitsch and Gries (2003), then, there is a reason for deep and water to be treated as collexemes in the preposition + premodified noun construction, i.e. in deep water, 
while for deep sleep the local co-occurrence should be enriched with the information gathered from a larger context, both local, i.e. the verb, and global, i.e. the syntactic pattern, in order to arrive at a viable interpretation. In other words, in order to elucidate the meaning of deep in deep sleep we need a larger context than in the case of deep water. Also, while the preposition may act as a profile determinant in the case of deep water, it is the verb and the syntactic schema which seem crucial for the interpretation of deep sleep. This is confirmed by the fact that deep sleep occurs with non-container prepositions, e.g. from, which is an unlikely pattern for deep water.

Let us now look at examples involving deep fear to see if the idealized conventional meaning is preserved. There are eight instantiations of deep fear in the $\mathrm{BNC}$, which are given below.

23) The need for excessive control in conversation can come from a deep fear that other people's ideas are threatening.

24) One more guilty secret that Maggie felt obliged to keep from everyone was the deep fear and disgust that she felt at the thought of sexuality.

25) The colour left her skin, her pale face showing a deep fear at the way he was crushing her to his body.

26) In no way had he been consciously sadistic over the earlier years, but he had a deep fear of women who took over, as his mother had done.

27) In England the desire for an "English" tradition is said to hide a deep fear of our present multi-cultural society, a determination to maintain our present class structure, the hierarchies of power which give Oxbridge dons their privileged and cushioned existence.

28) The warm, soft-seeming lead beneath her feet and the sharp-knapped flint and stone under her hand only partially secured her against the deep fear of falling.

29) A general war weariness, grievances over high taxation, and a deep fear amongst the Anglican majority of the population that the Church was now in greater danger from Protestant Nonconformists than it was from popery, all worked to the Tories' advantage.

30) "These men are torn between yearning to be close to a woman and having a deep fear of hostility towards them," says psychologist Dr Susan Forward.

Evidently, examples (23) to (30) are distantly, if at all, related to sentences including deep water and deep sleep. Firstly, containment prepositions are absent from the context of deep fear, which may be interpreted as downplaying the role of topological properties. Next, verbs co-occurring with deep fear seem to highlight the visibility/existence schema, as indicated by keep from (24), show 
(25) and hide (27). Moreover, there is a prepositional verb, secure against (28), which highlights the domain of danger within the conceptual matrix of deep fear. Furthermore, there is a substantial amount of postmodification elaborating deep fear. This is in the form of relative or appositive clauses as well as prepositional phrases.

As Kemmer (2005) convincingly argues, it is often the degree of a collostructional pull which determines how much "encyclopaedic" information needs to be retrieved in order to interpret an utterance. In other words, the less compatible a given item appears to be with the construction, or context within which it occurs, the more additional information, contributed, for instance, by other meaningful elements of the syntagmatic sequence, needs to be retrieved. This can be illustrated by the contrast between I gave it a little kick and I gave the lever (on the handlebar) a little kick (with my thumb) (see Kemmer 2005). While the first example seems to be readily interpretable within a limited context, the other one cannot be understood via referring to the conventional meaning of either the lexical item or the construction and hence, additional information, included in brackets, is needed.

The same tendency is observable when comparing deep water, deep sleep and deep fear. As already signalled above, the contextual reading of deep water is facilitated by an insignificant portion of the syntagmatic context, while in the case of deep fear a much larger framework is required. Moreover, the former phrase is in fact self-contained and its out-of-context interpretation may not differ much from that obtained through analyzing contextual clues. On the other hand, an isolated interpretation of deep fear, which is dominated by the aspect of intensity, becomes much less uniform once the phrase is placed within its natural context.

Consequently, the meaning of deep seems most schematic in the collocation with fear. To be more precise, in examples (23) to (30) above, deep can be interpreted as unconscious $(23,26)$, unacceptable $(24,27)$, or intense $(25,28,29$, 30 ). However, even those interpretations can only be taken as tentative proposals, which is due to the fact that the contextual elements perceived as meaningful, e.g. appositive clauses, are themselves rather schematic. In other words, contextual clues do not provide a stable interpretation of deep fear, which could be taken as evidence for a high degree of metaphoricity of the cluster.

All in all, it stands to reason to postulate that the amount of context necessary to interpret a given lexical unit will vary dependent on the level of schematicity of the item itself as well as other constructions within which it is situated. The higher the degree of idealized conventionality within a particular unit, the less context is needed to interpret it. However, in the case of abstract concepts, like fear, we apparently need all manner of information to describe its meaning. This postulate is similar to the constraint satisfaction approach to the 
processing of figurative language (McRae et al. 1998), where variability is perceived as the key notion in resolving lexical ambiguity. The model accounts for the integration of various sources of information by postulating that alternative syntactic, lexical and conceptual possibilities simultaneously compete for activation in meaning construction. Competition ends when one of the alternatives enables us to interpret the meaning of a given unit. Therefore, positing any dichotomies between the conventional and the encyclopaedic, the lexical and the grammatical or the syntagmatic and the paradigmatic seems pointless.

\section{Towards an integrated conceptual model}

A conceptual approach proposed within CMT is too rigid to account for the complexity of real data. For instance, while in a metaphor methodology deep has been uniformly interpreted as denoting intensity, a data-driven model presents a different semantic picture of the adjective. As a result of the critical evaluation of the possible interpretations of conventionality, which constitutes a core notion in top-down lexical approaches, we can now propose a more dynamic and usage-based model of a semantic description. The following postulates are of primary importance within the current proposal:

1) Meaning is a potential whose boundaries can be imposed only arbitrarily.

2) Meaning is thus an emergent and dialogic occurrence; a meaning of a unit is transitory in nature.

3) The meaning of a linguistic item can only be interpreted in context, and this should be maximally inclusive.

4) Thus, in order to interpret the meaning of a chosen unit all manner of contextual information should be summoned, including, at least, conventional and encyclopaedic knowledge, lexical and grammatical information as well as syntagmatic and paradigmatic clues.

5) Consequently, an item's informative potential will be different, depending, among others, on the context in which it is embedded.

6) The process of meaning interpretation is facilitated if a number of contextual clues converge. For instance, the same meaning is highlighted by various elements of the context.

7) The role of contextual information in meaning disambiguation is not uniform. It seems that the grammatical elements of meaning, e.g. prepositions and syntactic constructions, are, on the whole, more informative than content items (see Talmy 2000).

The above rather general postulates have the following implications for a methodology which is advocated here in order to describe the semantic structure of emotion terms. 
Firstly, we assume that abstract concepts, such as fear or anger, have their own internal structure, which is evidenced, for instance, by the fact that their collocational and/or grammatical patterns are fairly idiosyncratic (see Deignan $2005,2006)$. Hence, the primary role of the context is to highlight the already present features. Naturally, the attributes of fear are nowhere near as concrete as those of boxes, for instance. However, it can be tentatively assumed that the concept can be described against a domain matrix including existence, intensity, directionality or control (Solomon 1976; Frijda 1986; Kövecses 2000).

Moreover, in certain contexts the meaning of fear will be more salient than in others since the semantic features of many co-occurring elements will converge. For instance, the main function of the adjective in the premodifying construction is to accentuate certain dimensions of the following noun (see Evans 2006). Thus, adjectives referring directly to the attributes of fear, for instance, real, which highlights the existence schema, are considered to form more coherent and informative patterns than those indicating those dimensions only indirectly, e.g. deep. In other words, while both real and deep may in theory refer to certain parameters within the structure of the concept of fear, the former is assumed to be more informative than the latter.

Next, in order to establish the role of a given collexeme for the semantics of fear, we should check its conventional lexical and syntactic patterns. Then, the occurrence of these tendencies should be traced in the context of fear. If the degree of compatibility is high, particularly at the level of grammatical constructions, we can stop the process of disambiguation. Otherwise, other elements of the context need to be retrieved until a meaning is established. However, this does not mean that the results of the process of meaning construction will always render clear results. For instance, we might encounter contexts in which the adjective is not related to any of the possible dimensions of the concept of fear. Then, the adjective in the attributive construction can be perceived as denoting a general property schema since "[c]omplex arrays of vital relations can end up being compressed in the blend into the single vital relation of Property. The property safe in the blend compresses a complex counterfactual network, yielding expressions like "safe child," "safe jewels," and "safe distance" (Fauconnier - Turner 2002: 318). Alternatively, as we shall see in the case of cold fear, the adjective may belong to the category of determiners rather than content words.

The methodology outlined above is now going to be verified. Firstly, I will present a study of sick in order to further illustrate the proposed stages of methodology. Next, corpus examples of cold fear will be discussed in order to highlight particular relevance of the approach for the semantics of emotion terms. The analyses are qualitative in character and require further support and verification from quantitative studies. 


\subsection{Example 1: sick}

The most frequent domains to co-occur with the adjective sick include the following nouns: children, leave, man, people, person, child, joke, building, room, wards, woman, animals and bed.

Clearly, then, sick has a highly conventionalized link with the domain of living organisms, particularly humans, as evidenced by, for instance, sick children, sick man, or sick people. Moreover, the attribute highlighted by sick seems to be that of passivity, which is illustrated by examples (31) to (34). Moreover, there are no dominant prepositions or verbs which could serve as disambiguating clues. Thus, the combination seems meaningful by itself. Also, syntactic schemas, if at all, reinforce the idea of inactivity since the human participant is deprived of its canonical property - control.

31) I used to go to his characters for help as a Catholic might go to a priest or a sick man to his doctor.

32) There is in fact a fine line in Hunt's book in which he describes his reaction, on getting to Austria - Niki's home circuit - and learning that Niki was a very sick man indeed.

33) He might be a sick man, but he's proud.

34) He was suddenly an old, sick man.

The next group of conceptual domains for sick is instantiated by collocates denoting locations, e.g. sick ward, sick bed. Of the 12 concordances of sick bed in the BNC, 11 contain the preposition, from and on being the most frequent. Also, there are 11 cases of sick bed co-occurring with the possessive determiner, which is illustrated by examples (35) to (37) below.

35) "Get that woman out of my house," grandfather shouted from his sick bed.

36) She had learned her lines for her final scenes from her sick bed.

37) And her frail brother bravely struggled from his sick bed to be best man.

On the one hand, then, the preposition on, as well as the possessive, suggests the idea of proximity. On the other hand, though, from conveys the notion of separation. A sick bed, then, is a location about which people have rather ambivalent feelings. However, this bipolarity is not the conventional element of the semantics of sick. Rather, it is imposed on the adjective by means of contextual information. Likewise, it would be unfeasible to claim that the concept of cruelty belongs to the domain matrix of sick. Instead, it is the overall meanings of sentences (38) and (39) which enable us to interpret sick in this manner. 
38) The wartime government had promised the troops they would return to "homes fit for heroes to live in", but the sick joke was that you had to be a hero to survive in them.

39) For many, the idea of a free choice in housing is a sick joke, especially among the unemployed, those in insecure jobs, and for many in high house-price areas.

Finally, let us look at examples including sick fear.

40) Forester could simply melt away and leave the area, but his own freedom wasn't his main concern; he'd already spent a week away from Cumbria, and he had a sick fear of returning to find the clinic ruins empty and the valley returned to placid normality. (umotivated, unreasonable)

41) "Go to hell!" she burst out hoarsely and started to fight in deadly earnest, slapping and scratching at him, little cries of panic coming from the back of her throat as her mind flashed back into full operation and she realised with sick fear just how close she had come to the edge. (intense, provoking nausea?)

42) With sick fear in his stomach, Cardiff took her arm and guided her towards the side door. (unpleasant/provoking nausea)

Possible interpretations of sick in the above contexts, which are provided in brackets, point to an interesting co-relation between a conventional lexical element and a corresponding construction. Examples (41) and (42) could possibly be read as causing nausea, which is particularly motivated in the latter example in the context of his stomach. However, this interpretation of sick is conventionally bound to the predicative construction, as in I feel sick. The fact that a certain reading of sick is evoked in spite of a lack of correlation with its most prototypical syntactic schema can be explained through the notion of constructional schematicity.

To begin with, it should be stressed that certain grammatical patterns seem less meaningful than others. For instance, the premodifying slot in the attributive construction appears more schematic than the predicative position of the adjective. Thus, while adjectives such as cold or bright readily premodify fear, their meanings are highly unelaborated, and in some contexts they merely highlight the property schema. On the other hand, if the same adjectives were to occur in the predicative constructions, their meanings would have to be specific. In other words, if sick were to occur in *My fear was sick, it would be unacceptable due to a very clear defining function of the predicative construction, which would imply that one of the attributes of fear is canonical sickness. On the other hand, if sick fear appears in the context of (42), for instance, it is acceptable since the idea of sickness becomes attenuated as a result of a noncanonical syntactic context. 
The above-presented propensity towards schematicity in the attributive construction is best illustrated in example (40), where sick can probably be only disambiguated through recourse to what could be called a paradigmatic scaffolding. In other words, due to a lack of sufficient clues from the syntagmatic context of sick fear, we need to retrieve other examples of the have + adjective + fear pattern in order to find a semantic analogy between the adjectives. This is illustrated by examples (43) to (48) below.

43) But Charles had a nagging fear that it wasn't that, that Michael Banks really was trying, that he did go through the lines time after time in the evenings, but that his mind could no longer retain them.

44) It seemed a rather difficult thing to do, somehow, which surprised me, as I hadn't realized I still had some atavistic buried fear of him because he was black.

45) Grown men are still aware of this potential loss of self, and many have an instinctive fear of the "devouring" quality of women, since it can threaten their personal integrity.

46) In no way had he been consciously sadistic over the earlier years, but he had a deep fear of women who took over, as his mother had done.

47) Many mammals have an inborn fear of poisonous snakes and the defensive noises of a cornered snake are, of course, the spit and hiss.

48) Anyway, I've always had this real fear of me appearing in the Mail On Sunday with my eyes shut and looking pissed, with some caption underneath saying "Whose beer is it anyway?" or "Have I got booze for you".

The adjectives in the above contexts are all related to the domain of existence, which, as indicated in Section 5, is one of the dimensions of fear. Some of them are direct and straightforward, i.e. instinctive, atavistic, inborn, while others are more schematic and potentially ambiguous, i.e. deep or real. Clearly, existence is perceived through the prism of how conscious we are of a particular occurrence, which is reinforced by such contextual clues as realize (44), aware (45) or consciously (46). It seems, then, that in order to elaborate the meaning of certain adjectives premodifying abstract terms we need to summon all manner of information and no limits can be felicitously imposed.

The main aim of the above discussion was to demonstrate the intricacies involved in the process of meaning construction and interpretation. Evidently, the study was conducted in line with the conceptualist commitment since cognitive parameters, such as schematicity, complexity, or gradability, were observed. Now the need for a non-dichotomous approach to a linguistic analysis will be reinforced. 


\subsection{Example 2: cold fear}

Examples (47) to (55) have been retrieved from the BNC and arranged according to the perceived salience of attributes. As can be noticed, while certain interpretations, provided in brackets, are fairly straightforward, and will probably be shared by a large number of speakers, those at the end of the list remain ambiguous.

47) She struggled with the cold fear that had laid its hand on her. (control)

48) A cold fear gripped Connon's stomach. (control)

49) She stared back at him, cold fear numbing her heart. (control)

50) Cold fear filled every heart. (existence)

51) As he dressed for dinner in his room, Dorian remembered what he had seen and cold fear ran through him like a knife. (intensity, brevity)

52) Then, in the smoke and pain he smelt the fumes, the cold fear bursting through the ripped fuselage, the noise, the vibration, the acrid smell of cordite from the dulled barrels of a shotgun.(intensity, brevity)

53) I asked, with a cold fear in my heart. (existence?)

54) He was calmer, with the calmness of cold fear. (existence??)

55) Hooting with pleasure, trailing fortissimo, diminuendo, piano, to cold fear? (?)

Let us discuss a few tendencies in the above data, which seem consistent with the overall framework proposed here.

First of all, there is a relation between the quality of context and the likelihood of an unambiguous interpretation. In (47), (48) and (49) the suggested construal is facilitated by the non-schematic verbs: struggle, grip and numb. Moreover, in (47), the proposed reading is assisted by the semantics of the phrase laid hand on. Thus, the function of cold in examples (47) to (49) is to provide ontological strengthening to the modified noun. Construed as a canonical object, fear can then perform the role of an agent, as in (48) and (51), which is typical of neither cold nor fear in other contexts. Possibly, then, in the combination with fear, cold becomes schematized to such an extent that it is more related to the class of determiners than that of adjectives.

Another tendency is for a non-significant disambiguating role of schematic elements. The verb fill in (50) as well as fairly unelaborated prepositions with and to in examples (54) and (55) respectively are not of much help. At the same time, however, the ditransitive pattern and the locative interpretation of every heart in (50) converge to strengthen the existence schema proposed, this is not the case in (54) or (55), where cold fear is part of a highly schematic adverbial clause. 
Evidently, then, contextual information at any level, i.e. both local and global, needs to be meaningful to be valuable. Thus, cold seems more important for interpreting fear than deep, since it is more directly related to the structure of the concept.

\section{Conclusion}

A corpus-based integrated methodology proposed here provides a viable alternative to a conceptual metaphor approach to emotion terms. As argued above, a metaphor model is based on the static and abstract interpretation of a conventional sense, which violates the conceptualist commitment through, among others, the imposition of unmotivated dichotomies upon data. Consequently, words are associated with constant meanings, which, in the case of emotion terms, leads to rampant synonymy. For instance, in the metaphor model, deep occurs in the context of love, fear or sadness, and since the adjective invariably highlights the aspect of intensity, the three emotions may be regarded as virtually identical. On the other hand, an integrated approach concentrates on the natural context in which a particular linguistic unit occurs. Hence, unless deep love and deep fear, for instance, appeared in identical syntagmatic settings, deep could not be taken as referring to the same attributes in both contexts. Consequently, meaning potentials of individual units are taken as transitory and flexible, and the conceptual primitives through which aspects are highlighted are complex, dynamic and specific constructs. As a result, meanings of emotion terms are distributed rather than localized. In other words, since there is no definite profile determinant to be established for a given utterance, the meaning of a particular emotion noun is context-dependent. Thus, the aspects of an emotion concept highlighted in an integrated methodology typically diverge from those posited in an isolated model, in both qualitative and quantitative terms.

To be more specific, since particular aspects can be realized with various degrees of prominence, which is related to the nature of linguistic categories through which they are conveyed, apparently similar meanings are in fact dissimilar due to the effects of simulation and subjectification. In the same vein, since particular combinations of graded primitives are unlikely to recur, a usage-based approach implies that a particular emotion word "...may never be used twice with exactly the same meaning" (Langacker 2008: 50). 


\section{REFERENCES}

Allwood, Jens

2003 "Meaning potentials and context: Some consequences for the analysis of variation in meaning", in: Hubert Cuyckens et al. (eds.), 29-66.

Cuyckens, Hubert - René Dirven - John Taylor (eds.)

2003 Cognitive approaches to lexical semantics. Berlin: Mouton de Gruyter.

Boas, Hans C.

2003 A constructional approach to resultatives. (Stanford Monographs in Linguistics.)

Cameron, Lynne J. Stanford: Centre for the Study of Language and Information.

2003 Metaphor in educational discourse. London: Continuum.

Chłopicki, Władysław - Andrzej Pawelec - Agnieszka Pokojska (eds.)

2007 Cognition in language: Volume in honour of Professor Elżbieta Tabakowska. Kraków: Tertium.

Clark, Herbert H.

1996 Using language. Cambridge: Cambridge University Press.

Croft, William

2001 Radical construction grammar. Syntactic theory in typological perspective. Oxford:

Deignan, Alice Oxford University Press.

2005 Metaphor and corpus linguistics. Amsterdam: John Benjamins Publishing Company.

Deignan, Alice

2006 "The grammar of linguistic metaphors", in: Anatol Stefanowitsch - Stefan Th. Gries (eds.), 106-123.

Dirven, René

2005 "Major strands in Cognitive Linguistics", in: Francisco J. Ruiz de Mendoza Ibáñez Sandra Peña Cervel (eds.), 17-68.

Evans, Vyvyan

2006 "Lexical concepts, cognitive models and meaning-construction", Cognitive Linguistics 17(4): 491-534.

Evans, Vyvyan - Melanie Green

2006 Cognitive Linguistics: An introduction. Edinburgh: Edinburgh University Press.

Fauconnier, Giles - Mark Turner

2002 The way we think: Conceptual blending and the mind's hidden complexities. New York: Basic Books.

Fillmore, Charles J.

1985 "Frames and the semantics of understanding", Quaderni di Semantica 6: 222- 254.

Frijda, Nico H.

1986 The emotions. Cambridge: Cambridge University Press.

Geeraerts, Dirk

2003 "Decontextualizing and recontextualizing tendencies in 20th century linguistics and literary theory", in: Ewald Mengel et al. (eds.), 369-379.

2006 "Introduction: A rough guide to Cognitive Linguistics", in: Dirk Geeraerts (ed.), 1-28.

Geeraerts, Dirk (ed.)

2006 Cognitive Linguistics: Basic readings. Berlin - New York: Mounton de Gruyter. 
Goldberg, Adele E.

1995 Constructions: A construction grammar approach to argument structure. Chicago: The University of Chicago Press.

Giora, Rachel

1999 "On the priority of salient meanings: Studies of literal and figurative language", Journal of Pragmatics 31/7: 919-929.

Glynn, Dylan

2004 "Constructions at the crossroads: the place of construction grammar between field and frame", Annual Review of Cognitive Linguistics 2: 197-233.

Haiman, John

1980 "Dictionaries and encyclopedias", Lingua 50: 329-357.

Hampe, Beate - Joseph E. Grady (eds.)

2005 From perception to meaning: Image schemas in Cognitive Linguistics. Berlin: Mouton de Gruyter.

Hanks, Patrick

2006 "Metaphoricity is gradable", in: Anatol Stefanowitsch - Stefan Th. Gries (eds.),1736.

Hudson, Richard

2008 "Word grammar and construction grammar", in: Graeme Trousdale - Nikolas Gisborne (eds.), 257-302.

Kövecses, Zoltán

2000 Metaphor and emotion: Language, culture, and body in human feeling. Cambridge: Cambridge University Press.

2002 Metaphor: A practical introduction. Oxford: Oxford University Press.

Lakoff, George

1987 Women, fire and dangerous things: What categories reveal about the mind. Chicago: The University of Chicago Press.

Lakoff, George - Mark Johnson.

1980 Metaphors we live by. Chicago: The University of Chicago Press.

Langacker, Ronald W.

1987 Foundations of cognitive grammar. Vol. 1: Theoretical prerequisites. Stanford, CA: Stanford University Press.

2005 "Construction grammars: Cognitive, radical, and less so", in: Francisco J. Ruiz de Mendoza Ibáñez - Sandra Peña Cervel (eds.), 101-159.

2008 Cognitive grammar: A basic introduction. Oxford: Oxford University Press.

McRae, Kenneth J.- Michael Spivey-Knowlton - Michael K. Tanenhaus

1998 "Modelling the influence of thematic fit (and other constraints) in on-line sentence comprehension", Journal of Memory and Language 38: 283-312.

Mengel, Ewald - Hans-Jorg Schmid - Michael Steppard (eds.)

2003 Anglistentag 2002 Bayreuth. Trier: Wissenschaftliger Verlag.

Ruiz de Mendoza Ibáñez, Francisco J. - Sandra Peña Cervel (eds.)

2005 Cognitive Linguistics: Internal dynamics and interdisciplinary interaction. (Cognitive Linguistics Research 32.) Berlin: Mouton de Gruyter.

Solomon, Robert C.

1976 The passions. New York: Doubleday Anchor.

Steen, Gerard J.

2002 "Metaphor identification: A cognitive approach", Style 36/3: 386-407. 
2007 Finding metaphor in grammar and usage. Amsterdam: John Benjamins Publishing Company.

Stefanowitsch, Anatol

2006 "Words and their metaphors: A Corpus-based approach", in: Anatol Stefanowitsch Stefan Th. Gries (eds.), 63-105.

Stefanowitsch, Anatol - Stefan Th. Gries

2003 "Collostructions: Investigating the interaction between words and constructions", International Journal of Corpus Linguistics 8/2: 209-243.

Stefanowitsch, Anatol - Stefan Th. Gries (eds.)

2006 Corpus-based approaches to metaphor and metonymy. Berlin: Mounton de Gruyter.

Stern, Josef

2000 Metaphor in context. Cambridge, MA: The MIT Press.

Strugielska, Ariadna

2010 "Metafora konceptualna - między kategorią klasyczną a modelem potocznym", in: Zdzisław Wąsik - Aleksandra Wach (eds.), 109-121.

Szwedek, Aleksander

2007 "Polysemy and metaphorization", in: Władysław Chłopicki et al. (eds.), 255-272.

Taylor, John

2002 Cognitive grammar. Oxford: Oxford University Press.

Trousdale, Graeme - Nikolas Gisborne (eds.)

2008 Constructional approaches to English grammar. Berlin - New York: Mouton de Gruyter.

Vandeloise, Claude

1994 Spatial prepositions: A case study from French. Chicago: The University of Chicago Press.

Wąsik, Zdzisław - Aleksandra Wach (eds.)

2010 Heteronomie glottodydaktyki: Domeny, pogranicza i specjalizacje nauczania języków obcych. Księga jubileuszowa z okazji sześćdziesięciolecia urodzin prof. dr hab. Teresy Siek-Piskozub. Poznań: Instytut Filologii Angielskiej UAM.

Zlatev, Jordan

2005 "What's in a schema? Bodily mimesis and the grounding of language", in: Beate Hampe - Joseph E. Grady (eds.), 313-342.

\section{ELECTRONIC SOURCES}

BNC: The British National Corpus. [Available at: http:// www.view.byu.edu ED 01.2011].

Kemmer, Suzanne

2005 "Constructional profiles as the basis of semantic analysis", [Paper read at the Converging and Diverging Trends in Cognitive Linguistics conference, Dubrovnik, Croatia, 17-18 October. Available at: http://www.ruf.rice.edu/ kemmer/DUB3.ppt]. 